\title{
Corporeidade e motricidade na pedagogia do esporte: conhecimento e atitude indispensáveis para o ensino fundamental
}

\author{
Corporeity and motricity in sport pedagogy: \\ indispensable knowledge and attitude for elementary school education \\ Corporeidad y motricidad en la pedagogía del deporte: \\ conocimiento y actitud indispensables para la enseñanza fundamental
}

\author{
Wagner Wey Moreira ${ }^{1}$; AlCides José SCaGlia ${ }^{2}$; MARCuS Vinícius Simões de \\ CAMPOS $^{3}$ \\ Universidade Federal do TriângUlo Mineiro, UFTM, Uberaba-MG, Brasil \\ UNIVERSIDADE ESTADUAL DE CAMPINAS, UNICAMP, LIMEIRA-SP, BRASIL \\ UNIVERSIDAdE ESTADUAL DE CAMPINAS, UNICAMP, CAMPINAS-SP, BRASIL
}

\begin{abstract}
RESUMO
Corporeidade e motricidade são mais que termos conceituais, pois revelam atitudes necessárias para a incorporação desses conceitos. Visando enfocar a imprescindível presença destas no Ensino Fundamental, o presente artigo se propõe associar corporeidade e motricidade a uma pedagogia do esporte como elementos importantes para o trabalho de professores de Educação Física na escola. Com este foco o texto ficou estruturado da seguinte forma: no primeiro momento adentramos ao entendimento de corporeidade e motricidade para evitar equívocos na interpretação desses conceitos, o que já ocorre no mundo acadêmico brasileiro; no segundo momento afirmamos a importância da pedagogia do esporte para a criança e o adolescente do Ensino Fundamental.
\end{abstract}

Palavras-chave: Corporeidade. Motricidade. Pedagogia do Esporte. Ensino Fundamental.

\begin{abstract}
Corporeity and motricity are more than conceptual terms, since they reveal the necessary attitudes for the incorporation of these concepts. Aiming to focus the essential presence of these in Elementary School, the present article proposes to associate corporeity and motricity with sport pedagogy as an important element for Physical Education teachers in school settings. With this focus the text was structured in the following way: in the first moment we present our understanding of corporeity and motricity to avoid misunderstandings in the interpretation of these concepts, which already occurs in the Brazilian academic world; in the second moment we affirm the importance of sport pedagogy for children and adolescents in the Elementary School level.
\end{abstract}

Keywords: Corporeity. Motricity. Sport Pedagogy. Elementary School.

\section{RESUMEN}

Corporeidad y motricidad son más que términos conceptuales, pues revelan actitudes necesarias para la incorporación de esos conceptos. Con el objetivo de enfocar la imprescindible presencia de éstas en la Enseñanza Fundamental, el presente artículo se propone asociar corporeidad y motricidad a una pedagogía del deporte como elementos importantes para el trabajo de profesores de Educación Física en la escuela. Con este enfoque el texto quedó estructurado de la siguiente forma: en el primer momento adentramos al entendimiento de corporeidad y motricidad para evitar equívocos en la interpretación de esos conceptos, lo que ya ocurre en el mundo académico brasileño; en el segundo momento afirmamos la importancia de la pedagogía del deporte para el niño y el adolescente de la Enseñanza Fundamental.

Palabras clave: Corporeidad. Motricidad. Pedagogía del Deporte. Enseñanza Fundamental.

\footnotetext{
${ }^{1}$ Professor Adjunto da UFTM. E-mail: wmoreira@ef.uftm.edu.br

${ }^{2}$ Professor MS3 da UNICAMP, Campus Limeira-SP. E-mail: alcides.scaglia@gmail.com

3 Doutorando da Faculdade de Educação Física da UNICAMP, Campus Campinas-SP. E-mail: camposmvs@gmail.com
} 


\section{INTRODUÇÃOO}

Nas últimas décadas temos encontrado muitas produções de artigos científicos com o enfoque nos termos corporeidade e motricidade, alguns dos quais os associam a vertentes meramente técnicas e/ou a um olhar puramente fisiológico. O mesmo pode ser afirmado em relação às várias propostas relacionadas com a pedagogia do esporte, em que prevalece com ênfase o sentido do alto rendimento atlético.

Neste artigo procuramos caminhar na direção de mostrar a importância da vivência e do entendimento de corporeidade e de motricidade para a ação pedagógica do professor de Educação Física no Ensino Fundamental, a partir do desenvolvimento de uma pedagogia do esporte que apresente como pressuposto básico o sentido humano do indivíduo.

Temos consciência de que a tarefa é complexa e exige de todos nós determinação para seguir na direção de mudanças, afinal, somos professores na busca de projetos utópicos, o que nos faz percorrer permanentemente.

\section{CORPOREIDADE E MOTRICIDADE: MAIS HUMANO E MENOS TÉCNICO}

A base teórica para discutirmos corpo/corporeidade neste escrito está centrada em Novaes (2003), Rouanet (2003), Le Breton (2003), Nóbrega (2005; 2010), MerleauPonty (2011), Bento e Moreira (2012); Santin (2013), Gallo e Zeppini (2016), Moreira e Simões (2016). Já no que diz respeito ao estudo e às produções acerca da motricidade, nos apropriamos de Sérgio (1996), Trovão do Rosário (1999) e Moreira (2008).

Não é possível iniciar a reflexão sobre corporeidade se não nos ativermos a Maurice Merleau-Ponty, pensador proeminente no século XX, no qual encontramos a preocupação com o sentido de corporeidade. Merleau-Ponty (2011) já nos primeiros momentos de seu escrito atrelava a um corpo inteiro a significância do aprender pela sensibilidade considerando que a "[...] experiência sensível é um processo vital, assim como a procriação, a respiração ou o crescimento" (p. 31).

Outro ponto importante enfocado por esse autor, digno de atenção para os professores de Educação Física, é quando associa movimento e percepção, não como coisas distintas e vivenciadas em tempo e espaço diferentes. Saber, como diz MerleauPonty (2011, p. 161) que "[...] não há uma percepção seguida de um movimento, a percepção e o movimento formam um sistema que se modifica como um todo", pode reformular o trabalho em pedagogia do movimento no trato da corporeidade discente.

Corporeidade exige mais o sentido de descrever os fenômenos e menos o sentido de explicá-los e analisá-los. Afinal, todo o contexto da ciência é construído a partir do mundo vivido, ou seja, da experiência existencial do corpo sujeito no mundo.

No entanto, caminhar nestes pressupostos não é tarefa fácil. Novaes (2003, p. 9) afirma que "[...] o corpo humano só é corpo na medida em que traz em si mesmo o inacabado, isto é, promessa permanente de autocriação, e é isto que faz dele um enigma que a tecnociência pretende negar".

O mesmo autor, demonstrando preocupação com a forte tendência atual de buscar o sentido de perfeição corporal e associar isto à ideia de máquina em perfeito funcionamento, revela:

Se a perfeição é o esquecimento de certos fenômenos, o corpo contemporâneo é absolutamente imperfeito, uma vez que ele se tornou não apenas objeto de controvérsias, mas também campo de todas as experiências possíveis. O corpo transformou-se em máquina ruidosa a ser reparada a cada movimento. Máquina defeituosa, "rascunho" apenas, como descreve David 
Le Breton sobre a qual a ciência trabalha para aperfeiçoá-lo (NOVAES, 2003, p. 10).

Outro pensador que caminha no mesmo sentido da preocupação levantada anteriormente é Rouanet (2003, p. 40) ao afirmar: "O homem novo continua sendo um ideal, mas agora ele deve ser fabricado no laboratório, em vez de ser um produto social".

Interessante notar o paradoxo que a sociedade atual produz em relação à preocupação com o corpo humano. De um lado, produz pesquisas que identificam o gene do câncer, mas, por outro não conseguem descobrir o gene do capitalismo quando este torna possível a permanência da indústria produzindo vários elementos prejudiciais ao corpo, os quais permitem a propensão genética ao câncer (ROUANET, 2003).

Le Breton (2003) é mais um intelectual de nossos dias que enfatiza a preocupação de como a sociedade e a ciência na atualidade vem concebendo o corpo humano. Diz ele que "O corpo é visto por alguns entusiastas das novas tecnologias como um vestígio indigno fadado a desaparecer em breve" (p. 123). Comprova essa sua preocupação escrevendo:

O tátil converte-se em digital, o teclado substitui a pele, o mouse substitui a mão. E o interativo suplanta o dialógico, ainda que tecnicamente muitos progressos ainda precisem ser feitos. A sexualidade sem corpo e sobretudo visual, representa a hipertrofia do olhar; o tato é estimulado por conversores; eventualmente, também é auditiva, a partir de sons registrados anteriormente ou de um programa que associe gestos e emissões sonoras (LE BRETON 2003, p. 133).

Todo esse quadro nos remete à preocupação do caminhar para o lado oposto, nas trilhas da corporeidade e da motricidade.

Nóbrega (2005) deixa claro que somos corpos vivos e que para compreensão da realidade é necessário o sentir, o estar presente na relação com outros corpos. Daí a importância do sentido de corporeidade no qual o corpo e o mundo são presentidades inalienáveis, dependentes, construindo uma unidade existencial. Todo o seu referencial teórico centra-se nos escritos sobre corpo-próprio e motricidade formulados por Maurice Merleau-Ponty.

Aprimorando seus estudos, Nóbrega (2010) sempre nas trilhas de Merleau-Ponty revela que é na existência que imprimimos sentidos. "É a realidade do corpo que nos permite sentir e, portanto, perceber o mundo, os objetos, as pessoas. É a realidade do corpo que nos permite imaginar, sonhar, desejar, pensar, narrar, conhecer, escolher" (p. 11). Essa maneira de conceber/sentir o mundo demanda o entendimento e a atitude de corporeidade.

Corporeidade, num primeiro momento, parece um conceito simples e assim tem sido tratado por muitos pesquisadores. Ledo engano, mesmo porque corporeidade não nos dá um conceito objetivo e unívoco. Santin (2013) revela a complexidade do entendimento do termo corporeidade.

A compreensão da corporeidade por meio de conceitos e definições de manuais precisa ser completada pela observação das imagens de corpo que se constroem no imaginário social que, em última instância, são as que determinam a vivência corporal (p. 53).

Diz mais Santin (2013, p. 55): 
A imagem da corporeidade de nossa cultura racionalizada, cientificada e industrializada em nada garante o cultivo do corpo, ao contrário, o reduz a um objeto de uso, um utensílio, uma ferramenta a ser usada segundo a vontade de cada um ou, o que é pior, conforme os interesses econômicos, políticos e ideológicos de outros grupos.

Daí a necessidade de, na expressão do mesmo autor, reunir a ação de cultuar e de cultivar o corpo para se chegar à atitude da corporeidade.

Outra referência importante para o entendimento de corporeidade vem de Gallo e Zeppini (2016) quando, a partir dos argumentos de Foucault, Deleuze e Guattari, indicam novas perspectivas para o trato do assunto nestes nossos dias, buscando uma "Corporeidade que é parte ativa da constituição ética de si mesmo, explorada por Foucault na forma de uma estética da existência, trabalho de si sobre si mesmo, que nos constitui como sujeitos" (ZEPPINI, 2016, p. 130). Caminham mais os autores nas explicações deixando claro que as referências valem para "Não sujeitos assujeitados pelas relações de poder, mas sujeitos que se forjam e se constroem no seio mesmo dessas relações".

Ao refletir sobre pressupostos epistemológicos de corporeidade, vemos que ela nos faz entender o ser humano em sua existência, permitindo com isto novas maneiras de conhecer e conviver ética e socialmente. Por essa razão afirmamos ser corporeidade muito mais uma atitude que um conceito (MOREIRA; SIMÕES, 2016).

Associando definitivamente corporeidade ao ato educativo, é possível realçar o escrito de Bento e Moreira (2012, p. 135) quando demonstra:

\begin{abstract}
Advogar corporeidade, agora no sentido educacional, é lutar pelo princípio de uma aprendizagem humana e humanizante, em que, em sua complexidade estrutural, o ser humano passa a ser considerado, a um só tempo, totalmente antropológico, psicológico e biológico. O corpo do homem não é um simples corpo, mas corporeidade humana, só compreensível através de sua integração na estrutura social.
\end{abstract}

E quanto à motricidade? Podemos começar pelas argumentações desenvolvidas por Trovão do Rosário (1999) quando lembra aos estudiosos da motricidade humana a importância de se estudar o homem todo e, para esse fim, há que se possibilitar o diálogo permanente entre o corpo e o meio. Muitos dirão, de forma acertada, que este diálogo pode ter o nome de educação e ele dura toda a vida.

Mais à frente vamos tecer a importância da pedagogia do esporte associada ao sentido de motricidade, mas, já podemos destacar. "Assim se vão articulando palavras como assim se vão escolhendo os movimentos julgados mais úteis. A imitação nuns casos, e invenção noutros, vão valorizando uma panóplia sem a qual a educação quase seria impossível” (TROVÃO DO ROSÁRIO, 1999, p. 57). Esta afirmação já não demonstra a importância do se movimentar no esporte para o ato educativo? Educar não seria dar ênfases tanto à linguagem oral quanto à linguagem gestual? No entanto, verificamos a preocupação do ensino formal com a primeira e, de certa forma, o desleixo quanto à segunda. Hoje não vemos a possibilidade de uma educação da/pela motricidade no Ensino Fundamental. Falta conhecimento e disposição para a operacionalização desta na escola.

É importante também destacar que há em vários lugares a preocupação com as pesquisas e com o atentar para bases epistemológicas em motricidade humana. Sérgio (1996) revela que na Faculdade de Motricidade Humana, por exemplo, tem-se como objetivo de estudos o "[...] desenvolvimento humano através da motricidade, pelo 
estudo do corpo e das suas manifestações, na interacção dos processos biológicos com os valores sócio-culturais" (p. 15).

Indica mais o autor mostrando a importância de uma ciência da motricidade humana para a qual o ser humano é ao mesmo tempo sujeito e objeto do conhecimento e, para isso, essa ciência deve caminhar para "[...] articular a compreensão com a explicação, num ser inacabado, aberto e dinâmico, que se movimenta da imanência à transcendência, da natureza para a cultura" (SERGIO, 1996, p. 16).

Moreira (2008) demonstra a necessidade de alterarmos o foco quando se trata de estudar e vivenciar o movimento humano. Como primeiro ponto lembra que optar pela motricidade humana é advogar o estudo do ser humano que se movimenta intencionalmente na direção de auto superação. "Isto leva à necessidade de centrar o estudo em um corpo sujeito, existencial, indivisível, que se movimenta para garantir a vida tanto individual quanto coletiva" (MOREIRA, 2008, p. 87).

Como segundo ponto é necessário afirmar que o ser humano tende, enquanto vivo, à transcendência, das mais diversas formas que possamos concebê-la. Sempre queremos ser mais. Assim, a motricidade humana, enquanto concepção e área de estudo, pode, por exemplo, permitir que possamos identificar se a busca do ser mais e melhor não fere princípios éticos e nem prejudica a vida de outros seres humanos. Também a área pode proporcionar o entendimento de competição coexistindo com a cooperação, ambas explicitando motivação, prazer, ludicidade, elementos estes fundamentais para a convivência com o outro.

O terceiro ponto a ser focalizado pela teoria da motricidade humana é a constatação de que na corporeidade há a fusão do sensível, do inteligível e do motor, e por essa razão devemos desenvolver harmoniosamente esses três níveis constitutivos do humano no homem.

Como foi possível observar, corporeidade e motricidade são saberes teóricos e práticos que devem constar das preocupações educacionais. Entendemos que estes saberes podem ser melhor desenvolvidos e recebidos de forma mais interessante por alunos quando trabalhados na forma de pedagogias do esporte, claro, desde que estas contenham os elementos aqui descritos.

Por essa razão a nossa proposta, de associar corporeidade e motricidade à pedagogia do esporte com os argumentos agora a serem descritos.

\section{PEDAGOGIA DO ESPORTE: SUA IMPORTÂNCIA PARA O ENSINO FUNDAMENTAL}

Quando pensamos em pedagogia do esporte na tentativa de sistematizar na prática pedagógica os pressupostos teóricos e práticos da corporeidade e da motricidade, é necessário antes esclarecer seu papel e suas concepções de esporte, aluno e mundo.

A pedagogia do esporte é tema que podemos considerar embrionário enquanto pesquisa científica na área da Educação Física. Se em algumas partes do mundo ela já tem um bom número de produções científicas, no Brasil apenas agora há pesquisadores envolvidos com o tema. Neste sentido, quando pensamos em pedagogia do esporte consideramos o que chamaremos de novas tendências, fundamentalmente pautadas em autores como Bayer (1994), Freire (2002; 2003), Freire e Scaglia (2003), Garganta, 1995; 1998), Graça (1995), Greco e Benda (1998), Scaglia (2003; 2005; 2011), entre tantos outros.

É imprescindível esclarecer que não temos o objetivo de substituir a Educação Física escolar pela pedagogia do esporte. Não acreditamos que a última tenha como escopo e objetivo os princípios da primeira, mas sim, desenvolva conhecimentos que devem estar presentes no âmbito da escola quando esta trabalhar o esporte, ou seja, deva 
ser utilizada na escola enriquecendo as aulas de Educação Física com mais elementos teóricos e práticos para o ensino dos esportes (FREIRE; SCAGLIA, 2003).

Sendo o esporte não somente um fenômeno amplamente discutido na sociedade, mas também um dos conteúdos da Educação Física escolar no Ensino Fundamental, devendo ser trabalhado de forma orientada, sistematizada, dentro de um currículo e mediante a mediação de um professor, seu ensino, segundo, Reverdito e Scaglia (2009, p. 16), não deve ser entregue "[...] à intuição, ao acaso, principalmente quando observamos sua influência em diferentes setores da sociedade, tanto sobre processos operativos importantes da condição mais humana, quanto sobre a sua face mais irracional e destruidora".

Longe de levantar diferenças e demarcar territórios, compreendemos que a pedagogia do esporte carrega consigo elementos importantes para o ato educativo dentro da escola quando trabalhado o esporte, e deva ser orientada a partir das premissas colocadas por Freire (2000), nas quais o professor tem como meta ensinar esporte a todos, ensinar bem esporte a todos, ensinar mais que esporte a todos e ensinar os alunos a gostarem de esporte.

Segundo Freire e Scaglia (2003), o objetivo da disciplina Educação Física ou qualquer outra disciplina na escola é ensinar a viver em sociedade. Isto é enfatizado por Freire (2000) ao deixar claro que o esporte, enquanto conteúdo da Educação Física escolar, deve ser trabalho a partir de uma pedagogia que incentive os alunos não somente a exercerem ações descontextualizadas com seu cotidiano, mas encontrarem significados em suas práticas para a levarem por toda a vida.

A pedagogia do esporte tem o papel de ressignificar este fenômeno na vida dos alunos, compreendidos enquanto seres corpóreos situados em um espaço e em um tempo, buscando a todo momento a transcendência. Para isto, é necessário que a concepção de esporte de rendimento, hoje hegemônica em diversos universos, seja substituída por uma mais abrangente, a qual coloque o humano que o pratica no centro, como o esporte conceituado por Bento (2006, p. 3):

Este é concebido e interpretado como fenômeno polissêmico e realidade polimórfica, múltipla e não singular. $\mathrm{O}$ desporto é um construto que se alicerça num entendimento plural e num conceito representativo, agregador, sintetizador e unificador de dimensões biológicas, físicas, motoras, lúdicas, corporais, técnicas e táticas, culturais, mentais, espirituais, psicológicas, sociais e afetivas.

A definição anterior traz uma visão mais abrangente de esporte e, consequentemente, do ser humano que o pratica. Gostamos de refletir o esporte através destas lentes, pois redimensionam o foco, revelando que em qualquer prática esportiva há, para além de movimentos mecanizados, seres humanos se movimentando intencionalmente em busca de sua própria transcendência, atribuindo a todo novo lance novos significados, através do esporte, às suas vidas.

Quando trabalhado na escola, o esporte não deve ser conteúdo somente para transferência do que histórica e culturalmente foi desenvolvido pela humanidade até hoje sobre movimentos corporais, mas necessita ser inserido em um processo de ensino que vise mais que o rendimento, que busque a partir da prática o conhecimento do próprio corpo, do meio ambiente e da cultura da Educação Física, num movimento dialético permitindo a construção de novos significados para a vida dos alunos (FREIRE; SCAGLIA, 2003).

O esporte ensinado na escola deve propiciar aos alunos a capacidade de autocrítica além da preocupação com o desenvolvimento do repertório motor. 
A este respeito, Paes (2001) distingue duas formas de prática de esportes: a prática esportivizada e o esporte escolar. $\mathrm{O}$ mesmo autor refere-se à prática esportivizada como o ensino do gesto técnico de uma modalidade esportiva enquanto o esporte escolar é aquele que deve fazer parte da disciplina Educação Física, organizado, planejado e sistematizado.

A prática esportivizada não está somente na escola, mas em diversas escolinhas de esporte e clubes. Seus objetivos são o ensino da técnica estereotipada, descontextualizada do jogo e que busca a perfeição do movimento, tendo por consequências a exclusão de muitos, a despreocupação com o diálogo entre teoria e prática, e a concepção do esporte apenas como movimento mecânico separado de sua dimensão cultural.

Esta visão de esporte e de mundo ainda impera em diversas escolas, escolinhas de esportes ou clubes. Partindo de uma concepção instrumental do corpo, a pedagogia do esporte tradicional, ou comumente chamada tecnicista, separa o ser humano do movimento e traça o rendimento como seu ideal maior. "O objetivo do esporte na Educação Física escolar, assim como fora dela, nas escolas de esportes, é atuar como mecanismo inventor no processo de constituição do indivíduo, sendo este sujeito do aprendizado" (REVERDITO; SCAGLIA, 2009, p. 21).

Por outro lado, o esporte escolar, segundo Paes (2001), deve ser oferecido de forma que todos os alunos possam compreendê-lo integralmente, conhecendo suas diversas modalidades, e seu ensino deve abranger conhecimentos teóricos e práticos, oportunizando assim ao aluno vivenciar seus fundamentos, conhecer suas regras e conhecer sua história e evolução.

A pedagogia do esporte deve propiciar ao aluno a vivência de um ambiente de aprendizagem diferente daquele tradicional, no qual a aprendizagem da técnica é contextualizada com a tática, estratégia, contexto ou mais especificamente à prática esportiva em questão.

Os esforços da pedagogia do esporte no cenário esportivo atual e na prática esportiva dentro e fora da escola demonstra uma mudança paradigmática nessa disciplina, partindo de uma visão tradicionalmente mecânica para uma nova na qual se apoia nos pressupostos sistêmicos e da complexidade (GARGANTA, 1998; REVERDITO; SCAGLIA, 2009; SCAGLIA, 2005).

Nosso olhar a respeito desta possibilidade de quebra de paradigma da pedagogia do esporte acompanha uma transformação nas ciências da educação no último século, considerando que a visão mecânica já não se sustenta, havendo a necessidade do rompimento do paradigma cartesiano que norteou por muito tempo os pressupostos do ensino e da aprendizagem, colocando agora o corpo no centro da preocupação pedagógica (GALATTI et al., 2014; MOREIRA et al., 2006).

Segundo Scaglia e Reverdito (2016), essa mudança paradigmática espelha as contribuições de diferentes teorias da aprendizagem, as quais convergem em três grupos distintos ao longo da história da educação, a saber, as inatistas, as empiristas e as interacionistas. Concordamos com os autores no sentido de uma pedagogia do esporte que leve em consideração o aluno enquanto ser situado no mundo e participante do processo de aprendizagem, o qual responde particularmente a cada contexto. Neste sentido, as teorias interacionistas são as que melhor corroboram com esta visão de educação e, consequentemente, de Educação Física, pois estão conectadas às abordagens de ensino humanista, cognitivista, sociocultural e ecológica (SCAGLIA; REVERDITO, 2016).

É possível notar que as novas tendências em pedagogia do esporte derivam de diversas teorias da aprendizagem, como nos mostram Reverdito e Scaglia (2009). Estas, 
mesmo partindo de bases epistemológicas diferentes, convergem num entendimento sobre educação a partir da interação do sujeito consigo mesmo, com os outros e com o mundo.

Uma vez que trabalhar o esporte no seu contexto e ambiente é fundamental para a aprendizagem do esporte, podemos afirmar que para o professor atingir o âmago da prática esportiva ele deve se apropriar do jogo. Este é, como nos lembram Freire e Scaglia (2003, p. 31): "[...] uma categoria maior, uma metáfora da vida, uma simulação lúdica da realidade, que se manifesta, se concretiza, quando as pessoas praticam esportes, quando lutam, quando fazem ginástica, ou quando as crianças brincam”.

Através do jogo, como nos lembra Garganta (1995), é possível melhor trabalhar duas noções fundamentais no ensino dos esportes, em especial os coletivos: a inteligência e a cooperação.

A pedagogia do esporte na escola tem como foco principal o esporte que possibilite ao aluno incorporar conhecimentos para a vida através da vivência em ambiente de jogo, sendo este significativo, imprevisível, complexo e cooperativo.

Defendemos que associar as noções de corporeidade e motricidade com pedagogia do esporte é necessária à Educação Física escolar, pois estas podem propiciar a busca de uma educação mais humana. Talvez a aula de Educação Física, através da pedagogia do esporte, seja o melhor exemplo para justificar que a aprendizagem é para o corpo e não somente para a cabeça, pois ela tem o privilégio de poder contar com os jogos, pois estes são simulações da vida social, bem como microuniversos de nossa sociedade (FREIRE; SCAGLIA, 2003).

\section{CONSIDERAÇÕES FINAIS}

As ideias aqui descritas fazem parte de uma luta pelo que acreditamos, como amantes do esporte.

Cremos na possibilidade da Educação Física, enquanto disciplina curricular no Ensino Fundamental, poder incrementar uma pedagogia do esporte na qual estejam presentes os pressupostos da corporeidade e da motricidade, vivenciada pelos alunos e professores através do elemento jogo e este propiciar a aprendizagem esportiva para a vida.

Jogar é preciso, considerando que a vida fica mais significativa e com cores mais alegres a partir do momento que aprendemos e incorporamos os esportes através da pedagogia do esporte.

A pedagogia do esporte, calcada nos valores aqui delineados, permite um trabalho educativo em que jogo e esporte possam contribuir para possíveis alterações de atitudes éticas e estéticas. À luta, pois!

\section{REFERÊNCIAS}

BAYER, C. O ensino dos desportos coletivos. Lisboa: Dina Livros, 1994.

BENTO, J. O. Esclarecimentos e pressupostos. In: TANI, G; BENTO, J. O.; PETERSEN, R. D. S. (Orgs.). Pedagogia do desporto. Rio de Janeiro: Guanabara Koogan, 2006. p. 3-11.

BENTO, J. O.; MOREIRA, W. W. (Orgs.). Homo sportivos: o humano no homem. Belo Horizonte: Instituto Casa da Educação Física, 2012. p. 112-180.

FREIRE, J. B. Pedagogia do futebol. Londrina: Autores Associados, 2003.

FREIRE, J. B. Jogo: entre o riso e o choro. Campinas: Autores Associados, 2002. 
FREIRE, J. B. Pedagogia do esporte. In: MOREIRA, W. W.; SIMÕES, R. (Orgs.). Fenômeno esportivo no início de um novo milênio, Piracicaba: Editora UNIMEP, 2000, p. 91-96.

FREIRE, J. B.; SCAGLIA, A. J. Educação como prática corporal. São Paulo: Scipione, 2003.

GAlATTI, L. R.; REVERDITO, R. S.; SCAGLIA, A. J.; PAES, R. R.; SEONE, A. M. Pedagogia do esporte: tensão na ciência e o ensino dos jogos esportivos coletivos. Revista da Educação Física/UEM, v. 25, n. 1, p. 153-162, 2014.

GALLO, S.; ZEPPINI, P. S. “O que pode um corpo?”: perspectivas filosóficas para a corporeidade. In: MOREIRA, W. W.; NISTA-PICCOLO, V. L. (Orgs.). Educação física e esportes no século XXI. Campinas: Papirus, 2016. p. 107-131.

GARGANTA, J. O ensino dos jogos desportivos colectivos: perspectivas e tendências. Movimento, Porto Alegre, v. 4, n. 8, p. 19-27, 1998.

GARGANTA, J. Para uma teoria dos jogos desportivos colectivos. In: GARÇA, A.; OLIVEIRA, J. (Org.). O ensino dos jogos desportivos. 2. ed. Porto: Faculdade de Ciências do Desporto e Educação Física, 1995. p. 11-25.

GRAÇA, A. Os comos e os quandos no ensino dos jogos. In: GARÇA, A.; OLIVEIRA, J. (Org.). O ensino dos jogos desportivos. 2. ed. Porto: Faculdade de Ciências do Desporto e Educação Física, 1995. p. 27-34.

GRECO, P. J.; BENDA, R. N. Iniciação esportiva universal I: da aprendizagem motora ao treinamento técnico. Belo Horizonte: Ed. UFMG, 1998.

LE BRETON, D. Adeus ao corpo. In: NOVAES, A. (Org.). O homem-máquina: a ciência manipula o corpo. São Paulo: Companhia das Letras, 2003, p. 123-137.

MERLEAU-PONTY, M. Fenomenologia da percepção. 4. ed. São Paulo: Martins Fontes, 2011.

MOREIRA, W. W. Corporeidade e formação profissional: a importância da teoria da motricidade humana para a educação física. In: GOLIN, C. H.; PACHECO NETO, M.; MOREIRA, W. W. (Orgs.). Educação Física e motricidade: discutindo saberes e intervenções. Dourados: Seriema Indústria Gráfica e Editora, 2008. p. 79-95.

MOREIRA, W. W.; PORTO, E. R.; MANESCHY, P. P. ; SIMÕES, R. Corporeidade aprendente: a complexidade do aprender viver. In: MOREIRA, W.W. (Org.). Século XXI: a era do corpo ativo. Campinas: Papirus, 2006. p. 137 -150.

MOREIRA, W. W.; SIMÕES, R. Educação física, esportes e corporeidade: associação indispensável. In: MOREIRA, W. W.; NISTA-PICCOLO, V. L. (Orgs.). Educação física e esportes no século XXI. Campinas: Papirus, 2016, p. 133-149.

NÓBREGA, T. P. Uma fenomenologia do corpo. São Paulo: Livraria da Física Editora, 2010.

NÓBREGA, T. P. Corporeidade e educação física: do corpo-objeto ao corpo-sujeito. Natal: Editora UFRN, 2005.

NOVAES, A. A ciência no corpo. In: NOVAES, A. (Org.). O homem-máquina: a ciência manipula o corpo. São Paulo: Companhia das Letras, 2003. p. 7-14.

PAES, R. R. Educação física escolar: o esporte como conteúdo pedagógico do ensino fundamental. Canoas: Editora ULBRA, 2001.

REVERDito, R. S.; SCAGLIA, A. J. Pedagogia do esporte: jogos coletivos de invasão. São Paulo: Phorte, 2009. 
Wagner W. Moreira; Alcides J. Scaglia; Marcus V. S. de Campos

ROUANET, S. P. O homem-máquina hoje. In: NOVAES, A. (Org.). O homem-máquina: a ciência manipula o corpo. São Paulo: Companhia das Letras, 2003. p. 37-64.

SANTIN, S. Perspectivas na visão da corporeidade. In: MOREIRA, W. W. (Org.). Educação física e esportes: perspectivas para o século XXI. Campinas: Papirus, 2013. p. 51-69.

SCAGLIA, A. J. O futebol e as brincadeiras de bola. São Paulo: Phorte, 2011.

SCAGLIA, A. J. Jogo: um sistema complexo. In: VENÂNCIO, S.; FREIRE, J. B. (Org.). O Jogo dentro e fora da escola. Campinas: Autores Associados, 2005. p. 37-70.

SCAGLIA, A. J. O futebol e o jogo/brincadeira de bola com os pés: todos semelhantes, todos diferentes. 2003. 178 f. Tese (Doutorado em Educação Física) - Faculdade de Educação Física, Universidade Estadual de Campinas, 2003.

SCAGLIA, A. J.; REVERDITO, R. S. Perspectivas pedagógicas do esporte no século XXI. In: MOREIRA, W. W.; NISTA-PICCOLO, V. L. (Orgs.). Educação física e esportes no século XXI. Campinas: Papirus, 2016. p. 43-72.

SÉRGIO, M. Epistemologia da motricidade humana. Lisboa: Faculdade de Motricidade Humana, 1996.

TROVÃO DO ROSÁRIO, A. A motricidade humana e a educação. In: SERGIO, M. (Org.). O sentido e a acção. Lisboa: Instituto Piaget, 1999. p. 31-60.

Recebido em: 6 set. 2017.

Aprovado em: 27 out. 2017. 